\title{
A Study on Network and Multimedia Application to Chinese Language Acquisition
}

\author{
Haizhen Mo \\ Henan Institute of Science and Technology, Xinxiang, Henan Province, 453003, China \\ Huiqing Dong \\ Department of Foreign Languages, Northwest A\&F University, Yangling, Shaanxi Province, 712100, China
}

\begin{abstract}
Technology is playing an ever increasing role in foreign language education and more so for less commonly taught foreign languages like Chinese" (Zhao and Lai, 2009). Teaching and learning Chinese language with up-to-date technology aid is of vital significance nowadays. The study on the effect of network and multimedia application to Chinese language teaching and learning shows that students feel at home with this new teaching model since it is helpful to arouse students' interest in learning and to improve their learning efficiency, while quite a few problems are still persistent in the teaching aimed at developing students' learning autonomy, such as lack of consciousness of learning based on network and low abilities to learn autonomously from multimedia sources. To deal with these problems, some suggestions are put forward in the paper with typical considerations given to students' emotional factors and instructor's role in the pedagogical output and input process.
\end{abstract}

Index Terms-Chinese language acquisition, computer-aid teaching and learning, Great Wall Chinese Courseware, network and multimedia approach

\section{INTRODUCTION}

Most of our contemporary Nobel Prize accomplishments in natural sciences result from an integration of different disciplines, thus interdisciplinary study is gaining momentum in modern scientific research and development (Zhang, 2009). So does language acquisition pedagogical techniques (Li, 2012). Since 1990s, many achievements in foreign language teaching and learning with the aid of network and multimedia have been obtained (Warschauer and Kern, 2000). The rapid development of modern information technology has long been propelling the modernization process of the whole society, and irrevocably calls for modernization of present-day education (Hu, 2004; Chen, 2004). He (2008) writes that "Types of teaching materials should go along with the progress of information technology, and electronic courseware will gradually replace the conventional paper teaching materials, thus exuberating greatly the functions of conventional textbooks". Conventional teacher-centered language acquisition model, merely imparting language skills and knowledge (Cai, 2003; Cai and Wu, 2003; Zhu, 2004; Zhang and Wu, 2005), is not only hard to meet the practical demand of the new generation students, but also difficult to improve students' initiative abilities of using Chinese language. International Curriculum for Chinese Language Education, published by The Office of Chinese Language Council International (2008), clearly states that "The general objective of the international Chinese education is to help the learners to improve their Chinese proficiency, highlight their learning objectives, foster their abilities to combine self-directed learning and collaborative learning, form an effective strategy, and ultimately acquire language competence". In line with these new demands, several network and multimedia teaching courseware have come forward, including "Changcheng Hanyu"-Great Wall Chinese Multimedia Product for Teaching and Learning Mandarin, which has been standing out predominantly among others worldwide. Great Wall Chinese is a new Chinese teaching and learning system based on extensive network and cutting-edge multimedia technology. It integrates e-learning with etutoring (online or face-to-face tutoring), and provides a convenient, vivid and cost-effective teaching method (Hanban Great Wall Chinese Centre, 2009). The courseware is a time-space free media for learners at any time, in any place and at any level in China or overseas.

With the aim of making full use of network and multimedia technologies in language acquisition, an internet survey was conducted to investigate students' applicability, as well as the effectiveness and problems of the new teaching model.

\section{A. Subject of the Survey}

In the past two years, Great Wall Chinese has prevailed in over 70 Confucius institutes across the world for Chinese language teaching and learning. In March 2010, the author conducted a survey among a total of 150 students studying Chinese with the courseware at Confucius Institutes in Krakow, Poland, Konfuzius-Institute Nurnburg, Germany, Confucius Institute at the University of Sydney, Australia, and Confucius Institute at the University of Utah, USA, etc, with the aim of finding out about the effect of this computer technology on Chinese language acquisition, thus, 
assessing on the educational outcome from students' angle. The survey is an anonymous one, and with a feedback of 112 efficacious questionnaires finally.

\section{B. Content of the Survey}

The content of the survey mainly involves the degree of students' applicability to the courseware and evaluations of its effectiveness, and also evaluations of the effectiveness of using network and multimedia in assisting self study, the problems existed, and any suggestions or recommendations.

\section{RESULT OF THE SURVEY}

Network and multimedia model not only brings learners with shared information beyond time and space, but also leaves influence on learners' study methods and produces results with completely new concepts and manners. The survey result is measured with Likert Scale, and the data of the 112 efficacious questionnaires are assayed under the SPSS 3.0 Test Analysis for Surveys. Of the five ordered response levels from "strongly disagree" to "strongly agree" in Likert Scale, the middle "neutral" level is taken as a general divide benchmark, i.e. the median value, for the sake of apparent assessment. The bilateral four values are treated as either a summative positive levels evaluation or negative levels evaluation. The result of the survey shows that network and multimedia aid model is positively correlated with students' adaptation and progress, but it also suggests several problems students met in their study. The main results are summed up as follows.

\section{A. Network Teaching and Learning}

As a new educational technique, network Chinese teaching does not change the substance of educational process, but it changes the whole pattern of teaching (Xue, 2003). Students can arrange study schedules of their own and choose contents they are interested in. So network teaching and learning holds a strong to-and-fro pertinence to some extent.

(1) Chinese skills improved through network teaching and learning

In table 1, it can be seen clearly that 41 and 37.6 percent of students surveyed marked "listening and speaking ability" progress, 12.4 percent of students answered "reading ability", and 9 percent of students answered "writing ability".

TABLE 1

CHINESE SKILLS IMPROVED THROUGH NETWORK TEACHING AND LEARNING

\begin{tabular}{llc}
\hline item & $\begin{array}{l}\text { Efficacious surveyed } \\
\text { student number 112 }\end{array}$ & percentage \\
\hline Listening & 50 & 41.0 \\
Speaking & 46 & 37.6 \\
Reading & 15 & 12.4 \\
Writing & 11 & 9.0 \\
\hline
\end{tabular}

Table 1 shows that network teaching not only arouses students' interest in Chinese learning, but also contributes to the improvement of their listening and speaking abilities remarkably, in keeping with "foster their (students) abilities to combine self-directed learning and collaborative learning," put forward by International Curriculum for Chinese Language Education.

(2) Functions of network teaching and learning in Chinese acquisition

The answers of students surveyed are in order as follows: stimulating study interest, developing self-learning ability, giving full play to Human-Computer interaction, arousing study enthusiasm. From this, it can be seen that students generally consider that network teaching can stimulate Chinese learning interest, and is helpful in building up selflearning ability. Study enthusiasm refers to learners' positive sense inclination of desiring and exploring relevant knowledge. Enthusiasm is a prerequisite to every successful work. Therefore, in order to make students learn Chinese well, the first thing to do is to arouse their enthusiasm of Chinese learning. This survey shows that network teaching is an effective means of arousing students' enthusiasm.

(3) Whether students communicate with one another online

In the answers, 25.5 percent of students surveyed answered "often", 36.9 percent of students answered "sometimes", 32 percent of students answered "basically not", and 5.2 percent of students answered "never". These indicate that a bit over one quarter of students often communicate or cooperate in studying, and nearly 40 percent of students basically not or never communicate and cooperate. It shows that students have low awareness of developing inter-communications, promoting interstudy or doing cooperative learning by making use of internet; so teachers should strengthen their guidance in this field and initiate cooperative learning online among students, and also encourage students to work cooperatively.

(4) Network Chinese autonomous learning initiative, compared with traditional teaching

From table 2, it is shown that 27.9 percent of students surveyed answered "with full self-control and no need of teachers' supervision"; 60.1 percent of students answered "with good self-control, but is easily influenced by such factors as online chatting, music listening, game playing, etc."; 7.0 percent of students answered "with poor self-control and need assistant teachers in accompany"; 5.0 percent of students answered "lost in controlling study schedule and 
cannot accept this way of learning". Seen from the survey, close to 88 percent of students think their autonomous learning ability is good or great, but teachers' supervision or guidance are still needed; for the rest students having poor autonomous learning ability, they need teachers' instructions even more. When asked by the question of "Whether teacher's role of guidance, assistance, and supervision is important for your online learning?", 78.2 percent of students surveyed answered "important" or "very important", 13.5 percent of students answered "just so so", 8.3 percent of students answered "not important" or "it is not necessary". "More and more students would take up their curriculum in accordance with their interest orientation and social demand, instead of starting a subject with the jurisdiction of teacher's dictates as well as within an intrinsic logic of a specific subject. (Xiang, 2004)" Therefore, at the same time of prioritizing students as subject place, teachers' leading position during network teaching and learning can not be ignored completely. In this new teaching pattern, teachers represent prominently as guides, assistants, and organizers.

TALE 2

STUDENTS' SELF-EVALUATION OF THEIR NETWORK AUTONOMOUS LEARNING

\begin{tabular}{lll}
\hline Evaluation & $\begin{array}{l}\text { Efficacious surveyed student } \\
\text { number 112 }\end{array}$ & percentage \\
\hline $\begin{array}{l}\text { With full self-control and no need of teachers' } \\
\text { supervision }\end{array}$ & 34 & 27.9 \\
$\begin{array}{l}\text { With good self-control, but is easily influenced by } \\
\text { such factors as online chatting, music listening, } \\
\text { game playing, etc. }\end{array}$ & 74 & 60.1 \\
$\begin{array}{l}\text { With poor self-control and need assistant teachers } \\
\text { in accompany }\end{array}$ & 8 & 7.0 \\
$\begin{array}{l}\text { Lost in controlling study schedule, and cannot } \\
\text { accept this way of learning }\end{array}$ & 6 & 5.0 \\
\hline
\end{tabular}

(5) Study hours of network learning out of class

Network Chinese learning gives students greater free time and more space. From table 3, it can be seen that when asked by "How many hours do you need in network autonomous Chinese learning every week?", 14.7 percent of students answered "two and a half hours", 37.7 percent answered "five hours", and 47.6 percent answered "above 5 hours". It is shown that over eighty percent of students have the need of at least five hours to fill up their in-class or formal study. Though with abounding online network resources available on hand, the supplementary period time of study beyond class for students is an integral part in their network autonomous Chinese learning.

TABLE 3

WEEKLY HOURS STUDENTS NEED IN NETWORK AUTONOMOUS LEARNING

\begin{tabular}{lll}
\hline Hours & Efficacious surveyed & Percentage \\
& student number 112 & 14.7 \\
\hline 2.5 hours & 18 & 37.7 \\
5 hours & 46 & 47.6 \\
\hline Above 5 hours & 58 & \\
\hline
\end{tabular}

(6) Obstacles to network teaching and learning

Forty-eight percent of students surveyed answered "lack of sense and habit of learning Chinese by using internet"; 34.3 percent answered "inconvenient to get access to online network"; 7.1 percent answered "computer operating ability is limited"; 10.6 percent answered "poor in Chinese for following instructions". The survey shows that nearly half of the students admit that they lack for awareness and habit in network Chinese learning, and they wish to be rightly instructed and guided. 34.3 percent of students regard online resources access as an important requirement in Chinese learning and this shows that students rely much on computers and network, and computers play an important role in their learning. Only 7.1 percent of students think their computer operating abilities are the obstacle to network learning, and this tells that only a minority of students needs to improve their computer operating skills, i.e. they need to facilitate with the awareness of exploring and discovering in study by using online resources.

\section{B. Multimedia Teaching and Learning}

Multimedia aid Chinese teaching and learning can submerge learners into an environment of mutual interactions of sounds, lights and images, and stimulate their sense organs with an integrative approach to words, images, pictures and sounds. At the same time of receiving traditional aural information, learners can strengthen the effect of aural input through a vast amount of visual input, thus to better memorize acquired knowledge and skills (Xiong, 2002).

(1) Students' applicability to multimedia teaching

One third of students surveyed answered they adapted to multimedia teaching quickly, over a half got accustomed to gradually, and the rest felt a little difficult. This shows that more than the majority of students can adjust their study attitudes and change their studying habits initiatively and positively according to changes of teaching patterns and means, so as to conform to the new teaching methods, in spite of a few students who are still unfamiliar with multimedia teaching and are more used to traditional teaching patterns. It shows that approving and accepting the changes of teaching patterns is quite a long process for students, and that students differ greatly in studying methods and habits. For example, asked by the question "Multimedia, video, and blackboard, which teaching media is most 
effective?", 64.8 percent of students welcomed multimedia, 25.5 percent preferred video, and the rest 9.7 chose blackboard. It indicates that all teaching media have some pros-and-cons. Some students enjoy traditional teaching patterns, but most students prefer to the multimedia one, since it is a stronger incentive to sense organs, and makes teaching more imaginary, stereoscopic, and vivid, thus raising study efficiency. Therefore, multimedia teaching seems more accessible and sensible.

(2) Extent of students' attention focused in multimedia teaching milieu

Table 4 shows that, when asked by the question "Where do you focus your attention on when in multimedia teaching milieu?", 76 percent of students surveyed answered they focused on the teaching contents presented by multimedia, 16 percent answered teacher's implication of discourse, and 8 percent answered text books.

TABLE 4

CONTENTS STUDENTS FOCUS ON WHEN IN MULTIMEDIA MILIEU

\begin{tabular}{llc} 
& CONTENTS STUDENTS FOCUS ON WHEN IN MULTIMEDIA MILIEU \\
\hline Contents & Efficacious surveyed & Percentage \\
& student number 112 & 76.0 \\
\hline Multimedia & 93 & 16.0 \\
Textbooks & 19 & 8.0 \\
Others & 10 & \\
\hline
\end{tabular}

It can be seen from the above table, most of the students focus on the teaching contents presented by multimedia. It suggests that multimedia teaching improves students' attention and conforms to their cognitive law. Compared with textbooks, the use of multimedia in presenting teaching contents can better attract students' attention. Some relative investigation says the concentration ratio is the highest when many sense organs participate in studying activities (Peng and Chang, 2004). The investigation is consistent with the result of this survey.

(3) Interest of students in Chinese learning aroused with multimedia teaching

88.6 percent of students surveyed answered "(strongly) agree", while 11.4 percent answered "(strongly) disagree". This tells that the overwhelming majority agrees to the effect of multimedia teaching in arousing interest in Chinese studying.

(4) Students' initiative participation in multimedia learning

Seen from the table 5 below, some 20 percent of students surveyed held a negative point of view, and around 80 percent responded with an affirmative answer to get on the learning of Chinese with the aid of multimedia courseware on their own. It illustrates that in multimedia Chinese teaching, teachers should not rely on multimedia devices too much to the neglect of teaching interactivity with students. Teachers should pay attention to arouse students' participation awareness to accord with the teaching characteristics of language classes.

TABLE 5

STUDENTS’ INITIATIVE PARTICIPATION IN MULTIMEDIA LEARNING

\begin{tabular}{lll} 
& STUDENTS' INITIATIVE PARTICIPATION IN MULTIMEDIA LEARNING \\
\hline comment & Efficacious surveyed & Percentage \\
& student number 112 & \\
\hline Strongly disagree & 6 & 5.0 \\
Disagree & 10 & 8.0 \\
Neutral & 13 & 11.0 \\
agree & 42 & 34.0 \\
Strongly agree & 51 & 42.0 \\
\hline
\end{tabular}

(5) Problems met in multimedia milieu

To the query "unfamiliar with the functions of all the contents in the disks", 20 percent students surveyed answered "yes", to "too many contents there to differentiate what is primary from what is secondary", 48 percent students answered "yes", and with the question as "have no students or teachers to communicate with", 32 percent students answered "yes". The survey reflects that, in the process of multimedia Chinese teaching and learning, students need instructions and communications with study partners or teachers during their process as well as about their problems met in study so as to better improve their studies.

\section{RECOMMENDATIONS}

Although the idea of "students-centered" in multimedia and network teaching becomes more and more prioritized, teachers' leading role cannot be neglected either. Online resources are rich but indiscriminal, so if students are put in the vast ocean of internet assimilating knowledge by their own, it will be very difficult for language students. "The educator's expertise is valuable in helping learners select the most appropriate learning resources and sequence them in appropriate order. At the same time, educators need to help learners build their independent learning skills" (Zhao and Lai, 2009). Hence, teachers should give students proper instructions, e.g. teachers should supply students with relative websites in accordance with the need of study materials for them to surf the internet on purpose, but not to look for materials blindly getting half of the result with twice of the effort; teachers should not only arrange teaching schedule and materials to wait passively for students to accomplish, but to arrange proper study materials for students to refer to, so as to help students transit from the state of passive study to totally autonomous study. Teachers should make full use of web resources, and resources inside and outside courseware to arouse students' study enthusiasm, to guide students 
to learn knowledge and skills effectively, to adjust teaching schedule on demand of students' need, and to give students individualized help. At the same time, more team work among students is also included.

\section{CONCLUSION AND PROSPECT}

Although the survey scope of this study poses a certain extend of regionality, and due to the complexity of the subject content, the items designed in the survey is unable to cover the exhaustive aspects, the survey is still of much objectivity, thus demonstrating fundamentally that the Great Wall network and multimedia Chinese Courseware teaching model is generally approved and approbated by learners.

The network and multimedia language teaching methodology with its cutting-edge of creating virtual language atmosphere and with abundant provision of resourceful audio-visual materials not only provides teachers with new teaching means, but also promotes the development of students' autonomous and individualized study, diversifying the interactions among teachers, students and computers. This new teaching pattern gives a full play to the concept of modern quality education, i.e. students-centered, teachers-guided, and paying attention to fostering students' language communication ability. Along with the development of modern educational techniques, improvement of educational facilities and reformation of teaching concept, a new path of Chinese teaching pattern with excellent combination of computers and human will come of age.

Meanwhile, with the rapid economic development and phenomenal cultural impact of China on the world, Chinese language acquisition and application is coming into increasingly great demand. At present, there are 223,499 international students studying in China, among whom 13,516 are Chinese government sponsored in total. Among the figure 13,516, 3,365 of them is the sole increment of 2008. However, this quota only accounts to 6.05 percent of the whole cake among all studying in China from abroad. The Chinese government's projected target of scholarships would exceed over 260,000 in 2013 (Zhou and Zhang, 2009). At the same time, the National Consultative Committee on Racism and Interculturalism of Ireland (2008) testified that "the Chinese community is the second largest ethnic group after the Polish community in Ireland which represents a relatively new destination for Chinese emigrants and who have brought with them a hard-working ethos and a strong sense of family and community". The Department of the Taoiseach (2008) stipulated that one of the key actions in the Irish Government Actions to Build the Smart Economy Framework is: "We will continue to strengthen bilateral education relations between Irish and Chinese authorities at third level, including further development of economic and cultural links and the learning of the Chinese language". Set in this favourable backdrop of Sino-Irish government's full support and underpinned with the two Chinese language and culture research centres established in 2007 in University College Cork and University College Dublin, it is prospective that research into Chinese language pedagogical methodology with the state-of-art cyber-delivered products be soon perfected and further developed to satiate the unprecedented socioeconomic demands.

\section{ACKNOWLEDGEMENT}

This work was supported by Program for Science \& Technology Innovation Talents in Universities of Henan Province (HASTIT).

\section{REFERENCES}

[1] Cai, Jigang. (2003). Why Reform the Traditional College English Teaching Pattern. China University Teaching, 11, 25-26.

[2] Cai, Jigang \& Wu, Shixing. (2003). Importing Network \& Multimedia Technique to Reform Traditional Teaching Pattern. Foreign Language World, 6, 2-7.

[3] Chen, Jianlin. (2004). College English Curriculum Requirements: A Theoretical Understanding and Application. Educational Technology for Foreign Language Teaching, 6, 46-50.

[4] Department of the Taoiseach. (2008). Building Ireland's Smart Economy, A Framework for Sustainable Economic Renewal. Dublin: The Stationery Office.

[5] Hanban Great Wall Chinese Centre. (2009). A Brief Introduction of Great Wall Chinese. http://www.docin.com/p20882822.html. (Accessed 29/9/2012).

[6] $\mathrm{Hu}$, Long. (2004). Innovation is the Eternal Theme in Foreign Language Education Technique. Computer-assisted Foreign Language Education, 6, 78-80.

[7] Li, Weihong. (2012). Critical Analysis of Cooperative Learning in Chinese ELT Context. Journal of Language Teaching and Research, 5:1046-1050.

[8] National Consultative Committee on Racism and Interculturalism (NCCRI). (2008). Virtual City Twinning Project, An Education Toolkit for the European Year of Intercultural Dialogue. Dublin: NCCRI.

[9] Office of Chinese Language Council International. (2008). International Curriculum for Chinese Language Education. Beijing: Foreign Language Teaching and Research Press.

[10] Peng, Beiping \& Chang, Qing. (2004). The Practice and Exploration of the Multimedia Teaching of College English. Journal of Taiyuan University, 1, 51-54.

[11] Warschauer M. \& Kern R. (2000). Network-based Language Teaching: Concepts and Practice. Cambridge University Press).

[12] He, Qisen, Huang, Yuanshen \& Qin Xiubai. (2008). A Retrospect and Prospect of 30 Years of Language Teaching and Linguistic Studies. Language Teaching and Linguistic Studies, 6, 427-433. 
[13] Xiang, Xianming. (2004). Reform of University Teaching Ethos during Higher Education Popularization. Journal of Higher Education, 1, 75-79.

[14] Xiong, Jie. (2002). The Coordinated Application of Multimedia CAI and Traditional Teaching Mode in College English Teaching. Journal of Xidian University of Electronic Technology. 1, 91-95.

[15] Xue, Zhenhong. (2003). On Internet-Assisted College English Teaching. Journal of Shaoyang College, 4, 145-147.

[16] Zhang, Renlei and Wu, Min. (2005). An Analysis of Teaching Reform in Multimedia and Network College English. Heilongjiang Researches on Higher Education, 4, 119-121.

[17] Zhang, Zhiguo. (2009). Main Parts Research on Language Policy: Example of the Senior Language Research Centre in the University of Maryland. World Education Information, 7, 34-37.

[18] Zhao, Yong \& Lai, Chun. (2009). Technology and Chinese as a Foreign Language (CFL) Education. Confucius Institute. 2,33 35.

[19] Zhou, Yi \& Zhang, He. (2009). Applying the Scientific Development View on the State-Funded Education Abroad and Promoting the Cultivation of Advanced Professionals to Serve the National Strategy-Interviewing with Liu Jinghui, Secretary General of China Scholarship Council. World Education Information. 9, 14-15.

[20] Zhu, Fudao. (2004). Teachers' Leading Role under the Condition of Web-assisted College English Teaching. Foreign Language World, 1, 48-53.

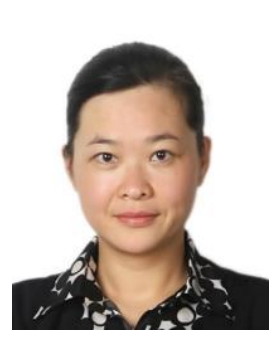

Haizhen Mo, associate professor at Henan Institute of Science and Technology, Xinxiang City, Henan Province, P. R. China. Dr. Mo got PhD of agrotechnology in 2007 at Jiangnan University, Wuxi, China and did post doctoral research at Wageningen University, the Netherlands. Dr. Mo is the young core teachers fostered and subsidized by Henan Province, excellent academic technology leaders at the provincial level.

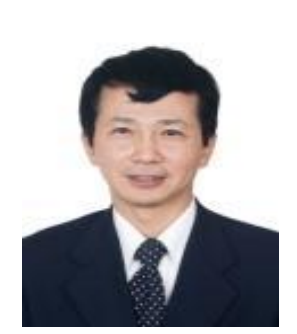

Huiqing Dong, Professor of Language and Culture at Northwest A\&F University of P. R. China, and Director of Education and Culture Section of Chinese Embassy in Ireland 